\title{
DIELECTRIC PROPERTIES OF BARIUM CRYSTAL GLASS
}

\author{
KATARÍNA FATURÍKOVÁ*, TADEÁŠ GAVENDA**, "MAREK LIŠKA***, ****, PETR VIŠČOR*, ***** \\ *FunGlass, A. Dubček University of Trenčin, Študentská 2, SK-911 50 Trenčin, Slovakia \\ **University of Chemistry and Technology, Prague, Faculty of Chemical Technology, \\ Technická 5, Prague, CZ-166 28, Czech Republic \\ ***VILA - Joined Glass Centre of the IIC SAS, TnUAD, FChPT STU, Študentská 2, Trenčin, SK-911 50, Slovakia \\ ****Institute of Inorganic Chemistry of Slovak Academy of Sciences, Dúbravská cesta 9, Bratislava, SK 845 36, Slovakia \\ *****EIS Laboratory, Skjoldenaesvej 17, 4174 Jystrup, Denmark \\ "E-mail: marek.liska@tnuni.sk
}

Submitted February 18, 2020; accepted May 7, 2020

Keywords: Impedance spectroscopy, Dielectric relaxation, Electrical conductivity

\begin{abstract}
The temperature dependence of impedance spectra of industrially produced (RONA, Lednické Rovne, Slovakia) barium crystal glass was studied. The linear dependence of complex impedance on the sample thickness was used for separating the bulk dielectric properties from the electrode boundary effects. The temperature dependence of direct current conductivity was evaluated from the Nyquist plots. The ZARC circular line was adjusted to the Nyquist plots by the least squares method. The distribution of relaxation times in impedance was evaluated this way. More detailed analysis of impedance spectra was performed by the equivalent circuit method in capacitance. Four relaxation processes were identified this way.
\end{abstract}

\section{INTRODUCTION}

The electrical impedance spectra of oxide glasses have been studied for decades [1-48]. As far back as in 1956, the dielectric relaxation of soda lime silicate glass for example, was studied by Taylor [44]. There are many types of glasses, where the electrical conduction is assumed to be ionic. Here, the best ionic conductors seem to be oxide glasses. Electrical conductivity of glass depends on alkali oxide content. The mobility of alkali ions, when present, is the determining factor. With increasing temperature the ionic mobility increases and resistivity of glass decreases. The ionic conductivities of glasses have been therefore studied extensively [1-4]. Many models have been suggested for the ionic conductivities of glasses [5], yet no definite and final, microscopic model exists. Conductivity data are often analyzed using the formalism of electrical modulus. In $[6,7]$, the influence of the composition on the conductivity spectra of different types of glasses has been studied by using complex electrical modulus. In [8] on the other hand, the authors studied the possible mechanisms of ion transport in sodium diborate glasses, modified by the addition of $\mathrm{PbO}, \mathrm{Bi}_{2} \mathrm{O}_{3}$ and $\mathrm{TeO}_{2}$. They concluded, that the structure of glasses significantly influences the conductivity. For a systematic study of electrical properties of materials, the Electrical Impedance Spectroscopy (EIS) is very suitable due to its superior position among other experimental electrical characterization methods [51, 57]. Being nondestructive, it is a very suitable method for determination of system's electrical impedance (resisti- vity), admittance (conductivity), capacitance (various polarization processes), and of many other electrical material parameters. Macdonald dealt with the history and principles of impedance theory [9-11]. Many various glassforming systems were studied using EIS. These include, for example, soda-lime glass [12, 13], silicate glasses [14, 15], $\mathrm{TeO}_{2}$ based glasses [16], borate glasses [17], $\mathrm{Li}_{2} \mathrm{O}-\mathrm{B}_{2} \mathrm{O}_{3}-\mathrm{Dy}_{2} \mathrm{O}_{3}$ glasses [18], $\mathrm{MoO}_{3}-\mathrm{Fe}_{2} \mathrm{O}_{3}-\mathrm{P}_{2} \mathrm{O}_{5}$; $\mathrm{SrO}-\mathrm{Fe}_{2} \mathrm{O}_{3}-\mathrm{P}_{2} \mathrm{O}_{5}$ glasses [19], lithium-indium-phosphate glasses [20], lithium borosilicate glasses [21], magnesium-telluride glasses [22], $\mathrm{TeO}_{2}-\mathrm{LiO}_{0,5}-\mathrm{LiX}(\mathrm{X}=\mathrm{F}$, $\mathrm{Cl})$ glassy system [23], $\mathrm{SiO}_{2}-\mathrm{Li}_{2} \mathrm{O}: \mathrm{Nd}_{2} \mathrm{O}_{3}$ glasses [24], iron oxide doped $\mathrm{Na}_{2} \mathrm{O}-\mathrm{CaO}-\mathrm{SiO}_{2}$ glasses [25], barium aluminoborate glasses [26], silicate-phosphate glasses [27], vanadium-telluride glasses with low and high content of $\mathrm{Ag}_{2} \mathrm{O}$ and $\mathrm{AgI}$ [28], $\mathrm{Ag}_{2} \mathrm{O}-\mathrm{B}_{2} \mathrm{O}_{3}-\mathrm{P}_{2} \mathrm{O}_{5}-\mathrm{TeO}_{2}$ glasses [29], $\mathrm{CaBi}_{2} \mathrm{O}_{7}$ glass [30], and silica-titania glasses [31]. The EIS analysis of $\mathrm{Bi}_{4} \mathrm{TiO}_{3} \mathrm{O}_{12}$ glass [32], $\mathrm{TeO}_{2}-\mathrm{SeO}_{2}-\mathrm{Li}_{2} \mathrm{O}$ nano glass system [33] and $\mathrm{PbO}$. $\mathrm{Bi}_{2} \mathrm{O}_{3} \cdot \mathrm{Ga}_{2} \mathrm{O}_{3}$ glass [34] has been also performed.

The EIS method is also useful for the study of glass crystallization kinetics. It is capable of identifying the crystallization peaks under small heating rates better than DTA technique [35, 36]. It was proven [37] that changes in electrical resistivity can identify the crystallization peaks in bulk samples of silicate-phosphate glass.

It seems that the electrical conductivity in oxide glasses is related to their dielectric relaxation. Shimikawa [38] for example, proposed a general model for the relationship between the dielectric relaxation and the electrical conductivity, regardless of the composition 
of the glass and type of conductive mechanism. The dielectric relaxation in different types of glass was studied, e.g. soda-lime-silicate glass containing small amount of $\mathrm{Fe}_{2} \mathrm{O}_{3}$ [25], silica glasses [39], $\mathrm{SiO}_{2}$ glass [40], sodalime-silicate glass [41], and $\mathrm{CaO}-\mathrm{Bi}_{2} \mathrm{O}_{3}-\mathrm{B}_{2} \mathrm{O}_{3}$ glasses [42]. With theory and experimental measurements of dielectric relaxation in glass dealt in 1974 M. Tomozawa [43].

As can be seen, typically, the two-three component glass-forming systems were studied. The present work deals with the multicomponent barium crystal glass produced by RONA glassworks, Lednické Rovne, Slovakia. At present, the dielectric properties of domestic glassware can be considered as important in connection with broad use of microwave ovens in gastronomy.

\section{EXPRIMENTAL}

The barium crystal glass produced by RONA glassworks (www.rona.sk) was used in this study. The chemical composition of studied glass is listed in the Table 1 [49]. Only the main components are given.

Table 1. The composition (wt. \%) of studied barium crystal glass.

\begin{tabular}{cccccccc}
\hline \multicolumn{7}{c}{ Oxide (wt. \%) } \\
\hline $\mathrm{SiO}_{2}$ & $\mathrm{Na}_{2} \mathrm{O}$ & $\mathrm{K}_{2} \mathrm{O}$ & $\mathrm{CaO}$ & $\mathrm{Al}_{2} \mathrm{O}_{3}$ & $\mathrm{BaO}$ & $\mathrm{ZnO}$ & $\mathrm{TiO}_{2}$ \\
\hline 69 & 10 & 4 & 8 & 1 & 6 & 1 & 1 \\
\hline
\end{tabular}

Circular glass samples with the thickness of $(0.7$, 1.0, 1.7, and 2.5) $\mathrm{mm}$ were cut by diamond saw and polished. Masked samples were covered by circular $\mathrm{Au}$ layer of approximately $300 \mathrm{~nm}$ thickness by magnetron sputtering performed by sputter coater Bal-Tec SCD 500. The diameter of Au electrodes was $16 \mathrm{~mm}$ from bottom side and $18 \mathrm{~mm}$ from upper side. Thus the average surface value of $2.278 \cdot 10^{-4} \mathrm{~m}^{2}$ was used as contact surface $A$. The impedance spectra were measured in the frequency range $f=\left(4 \cdot 10^{-3} \cdot 10^{6}\right) \mathrm{Hz}$ by Solartron Analytical Modulab ECS - MTS in configuration $\mathrm{MAT}+\mathrm{MFRA}+\mathrm{MREF}+\mathrm{FMA}$. In this frequency range 85 equidistant points $\left(f_{i}, i=1,2, \ldots 85\right)$ on the logarithmic frequency scale were measured. Each sample was measured twice in the same prescribed time - temperature regime at temperatures $(50,100,150,200,250$, $300,350$, and 400$){ }^{\circ} \mathrm{C}$. The temperature was increased to prescribed value by the heating rate of approx. $0.25^{\circ} \mathrm{C} \cdot \mathrm{min}^{-1}$. After isothermal dwell of 2 hours the impedance spectrum was measured. After measurement the heating and measurement at next temperature followed. After the measurement at $400{ }^{\circ} \mathrm{C}$ the sample was cooled to the room temperature. After 48 hours the measurement was repeated. The average of two impedance spectra obtained at each temperature was used for the further study.

\section{RESULTS AND DISCUSSION}

The complex impedance $Z^{*}=Z_{\text {re }}+i Z_{\text {im }}$ can be considered as the sum of the electrode-boundary impedance $Z_{\mathrm{A}}^{*}$, and the bulk impedance $Z_{\mathrm{B}}^{*}$. If the linear dependence of bulk impedance on the sample thickness $d$ is assumed, then

$$
\begin{gathered}
Z_{\mathrm{re}}(\omega)=Z_{\mathrm{re}, \mathrm{A}}(\omega)+Z_{\mathrm{re}, \mathrm{B}}(\omega) d \\
Z_{\mathrm{im}}(\omega)=Z_{\mathrm{im}, \mathrm{A}}(\omega)+Z_{\mathrm{im}, \mathrm{B}}(\omega) d
\end{gathered}
$$

where $\omega$ is the angular frequency $(\omega=2 p f)$. The values of $Z_{\mathrm{re}, \mathrm{A}}\left(w_{i}\right), Z_{\mathrm{im}, \mathrm{A}}\left(w_{i}\right), Z_{\mathrm{re}, \mathrm{B}}\left(w_{i}\right)$, and $Z_{\mathrm{im}, \mathrm{B}}\left(w_{i}\right)$ were obtained by linear regression analysis by minimizing the sum of squares of deviations between measured and calculated real/imaginary part of impedance for each measured angular frequency $w_{i}(i=1,2, \ldots 85)$ :

$$
\begin{aligned}
& S\left[Z_{\mathrm{x}, \mathrm{A}}\left(\omega_{i}\right), Z_{\mathrm{x}, \mathrm{B}}\left(\omega_{i}\right)\right]=\sum_{j=1}^{4}\left[Z_{\mathrm{x}}\left(\omega_{i}\right)-\right. \\
& \left.Z_{\mathrm{x}, \mathrm{A}}\left(\omega_{i}\right)-Z_{\mathrm{x}, \mathrm{B}}\left(\omega_{i}\right) d_{j}\right]^{2}=\text { min., } \quad \mathrm{x}=\text { re, im }
\end{aligned}
$$

where $d_{j}=\{0.7,1.0,1.7,2.5\} \mathrm{mm}$.

The quality of obtained results can be estimated by the values of standard deviations $s\left(Z_{\mathrm{re}, \mathrm{A}}\left(w_{i}\right)\right), s\left(Z_{\mathrm{im}, \mathrm{A}}\left(w_{i}\right)\right)$, $s\left(Z_{\mathrm{re}, \mathrm{B}}\left(w_{i}\right)\right)$, and $s\left(Z_{\mathrm{im}, \mathrm{B}}\left(w_{i}\right)\right)$ obtained as the result of the linear regression. As an example the results obtained at temperature $250{ }^{\circ} \mathrm{C}$ for real and imaginary part of bulk impedance are presented in the Figure 1 (the standard deviations are plotted as error bars).

In the next step the bulk impedance was analyzed using the Nyquist plots representation $-Z_{\mathrm{im}, \mathrm{B}}=f\left(Z_{\mathrm{re}, \mathrm{B}}\right)$. Despite some its drawbacks that can be found in literature [10, 50-53], it has been chosen for the purpose of this article, as reasonably illustrative impedance representation. Moreover this representation is still widely used in the study of dielectric properties of oxide glasses. The analyzed data were described by the depressed semicircle (so called ZARC circuit) [52, 53]:

$$
Z_{\mathrm{B}}^{*}(\omega)=\frac{R}{1+\left(i \omega \tau_{\sigma \varepsilon}\right)^{\alpha}}
$$

where $R$ is the direct current (DC) bulk resistance, $\tau_{\sigma \varepsilon}$ is the characteristic bulk conducto-permittivity relaxation time, and the exponent $\alpha(0<\alpha \leq 1)$ determines the width of modeled relaxation time distribution (with decreasing $\alpha$ value the width increases). The experimental data were fitted by the depressed semicircle by minimizing the sum of squares between experimental and calculated $-Z_{\mathrm{im}, \mathrm{B}}$ values. The bulk relaxation time $\tau_{\sigma \varepsilon}$ was estimated from frequency value, $f_{\max }$, at which the $-Z_{\text {im }, \mathrm{B}}$ reaches maximum by:

$$
\tau_{\sigma \varepsilon}=\frac{1}{2 \pi f_{\max }}
$$

The $R$ value was estimated from the endpoint where the semicircle reaches the zero $Z_{\text {im }}$ value and the $\alpha$ value was calculated from the slope of the tangent to the origin of the depressed semicircle. This is illustrated in the Figure 2 where the Nyquist plot for $150{ }^{\circ} \mathrm{C}$ is presented. 


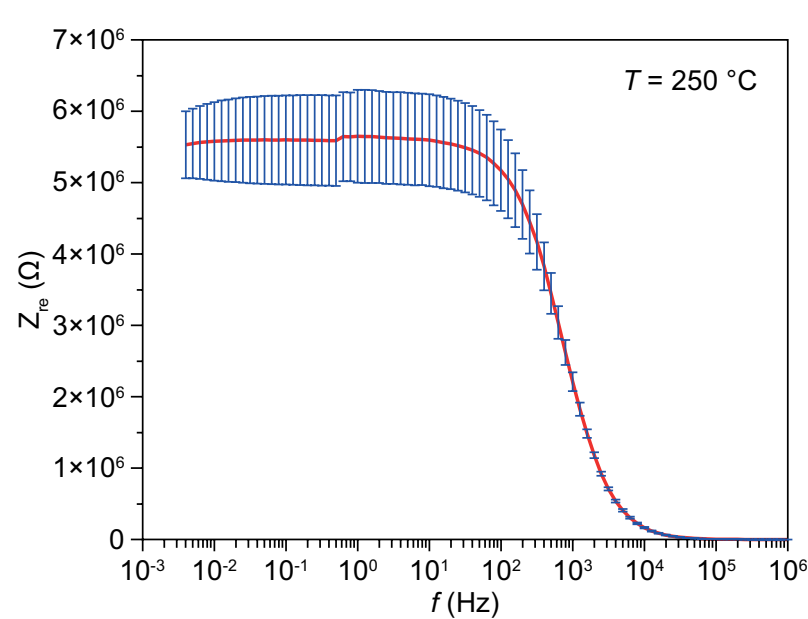

a)

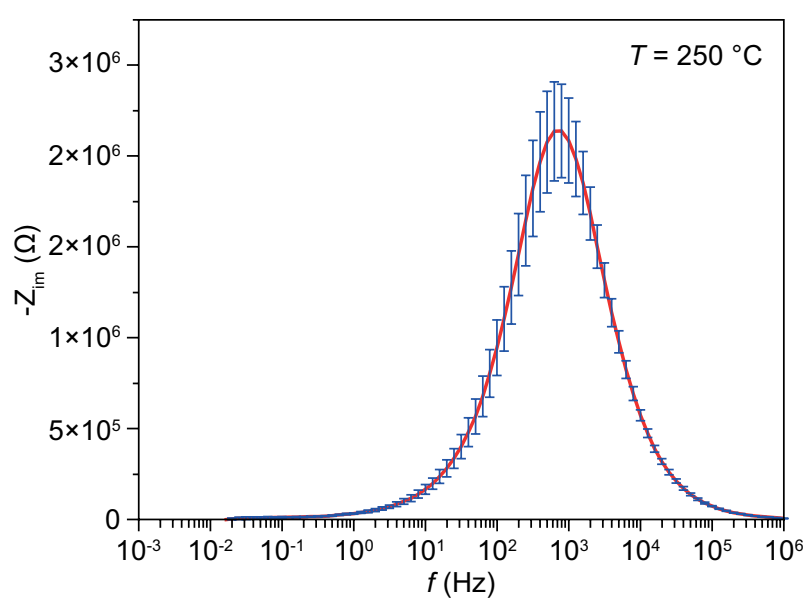

b)

Figure 1. The real $\left(Z_{\mathrm{re}, \mathrm{B}}\right)$ and imaginary $\left(Z_{\mathrm{im}, \mathrm{B}}\right)$ part of bulk impedance.

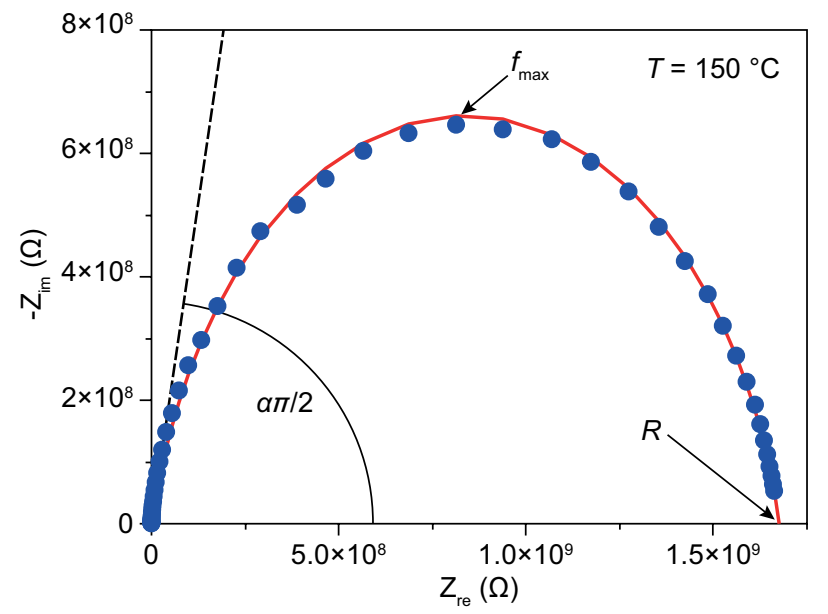

Figure 2. Estimation of $R, f_{\max }$, and $\alpha$ parameters from the ZARC in Nyquist diagram.

From the resistance $R$ the specific resistance $\rho_{\text {DC }}$ and the conductivity $\sigma_{\mathrm{DC}}$ were evaluated:

$$
\sigma_{\mathrm{DC}}=\frac{1}{\rho_{\mathrm{DC}}}=\frac{A}{R_{d}}
$$

where $A$ is the average surface of sputtered electrodes $\left(A=2.278 \cdot 10^{-4} \mathrm{~m}^{2}\right), d$ is the sample thickness (i.e. $0.001 \mathrm{~m}$ for data obtained from linear regression of complex impedance thickness dependence) and $R$ is the DC resistance obtained from the Nyquist plot. The obtained results are summarized in the Table 2. As an example the Nyquist plots for temperature $(50,100,200$, $250,300$, and 400$){ }^{\circ} \mathrm{C}$ are plotted in the Figure 3 . It is worth noting that the ZARC method can be used even in the case when the experimental data form only the beginning part of the ZARC semicircle (see $T=50{ }^{\circ} \mathrm{C}$ in the Figure 3). On the other hand the parameters obtained from such data have to be considered as rough estimates only (with the exception of the $\alpha$ parameter obtained from the tangent to the beginning part of the ZARC semicircle).
The dependence of the natural logarithm of bulk relaxation time $\tau_{\sigma \varepsilon}$ (in seconds) and of the DC conductivity $\sigma_{\mathrm{DC}}$ (in $\mathrm{S} \cdot \mathrm{m}^{-1}$ ) is plotted against the reciprocal thermodynamic (absolute) temperature, $T$, in the Figure 4. In both cases the linear dependence is found, namely:

$$
\begin{aligned}
& \ln \left(\tau_{\sigma \varepsilon}\right)=(-32.40 \pm 0.18)+\frac{12540 \pm 88}{T} \\
& \ln \left(\sigma_{\mathrm{DC}}\right)=(9.89 \pm 0.09)-\frac{12525 \pm 42}{T}
\end{aligned}
$$

The standard deviations of approximation $S_{\text {apr }, \tau}=$ $=0.092$, and $s_{\mathrm{apr}, \sigma}=0.044$ indicate the ideal linearity on the level of experimental noise. This can be seen as some kind of validation of results obtained by the ZARC method. From the slopes of linear dependencies the same values of activation energy were obtained for $\tau_{\sigma \varepsilon}$ and $\sigma_{\mathrm{DC}}$ :

$$
\begin{gathered}
E_{\tau}^{\neq}=(104.3 \pm 0.7) \mathrm{kJ} \cdot \mathrm{mol}^{-1}=(1.08 \pm 0.01) \mathrm{eV} \\
E_{\sigma}^{\neq}=(104.1 \pm 0.4) \mathrm{kJ} \cdot \mathrm{mol}^{-1}=(1.079 \pm 0.004) \mathrm{eV}
\end{gathered}
$$

Table 2. The results obtained from the Nyquist plots analysis - bulk relaxation time $\tau_{\sigma \varepsilon}$, DC conductivity $\sigma_{\mathrm{DC}}, \mathrm{DC}$ resistance $\rho_{\text {DC }}$, and parameter $\alpha$ (Equation 4 ) of the ZARC circuit.

\begin{tabular}{ccccc}
\hline $\begin{array}{c}\text { Temp. } \\
\left({ }^{\circ} \mathrm{C}\right)\end{array}$ & $\begin{array}{c}\tau_{\sigma \varepsilon} \\
(\mathrm{s})\end{array}$ & $\begin{array}{c}\sigma_{\mathrm{DC}} \\
\left(\mathrm{S} \cdot \mathrm{m}^{-1}\right)\end{array}$ & $\begin{array}{c}\rho_{\mathrm{DC}} \\
(\Omega \cdot \mathrm{m})\end{array}$ & $\alpha$ \\
\hline $50 \neq$ & 31.75 & $3.040 \cdot 10^{-12}$ & $3.289 \cdot 10^{11}$ & 0.904 \\
100 & 3.176 & $5.541 \cdot 10^{-11}$ & $1.805 \cdot 10^{11}$ & 0.859 \\
150 & $6.336 \cdot 10^{-2}$ & $2.617 \cdot 10^{-9}$ & $3.821 \cdot 10^{8}$ & 0.850 \\
200 & $3.176 \cdot 10^{-3}$ & $6.044 \cdot 10^{-8}$ & $1.655 \cdot 10^{7}$ & 0.846 \\
250 & $2.004 \cdot 10^{-4}$ & $7.830 \cdot 10^{-7}$ & $1.277 \cdot 10^{6}$ & 0.847 \\
300 & $2.522 \cdot 10^{-5}$ & $6.276 \cdot 10^{-6}$ & $1.593 \cdot 10^{5}$ & 0.852 \\
350 & $5.033 \cdot 10^{-6}$ & $3.685 \cdot 10^{-5}$ & $2.714 \cdot 10^{4}$ & 0.841 \\
400 & $1.004 \cdot 10^{-6}$ & $1.705 \cdot 10^{-4}$ & $5.864 \cdot 10^{3}$ & 0.820 \\
\hline \#) Only rough estimates of $\tau_{\sigma \varepsilon}, \sigma_{D C}$ and $\rho_{D C}$ are reported for $50^{\circ} \mathrm{C}$
\end{tabular}




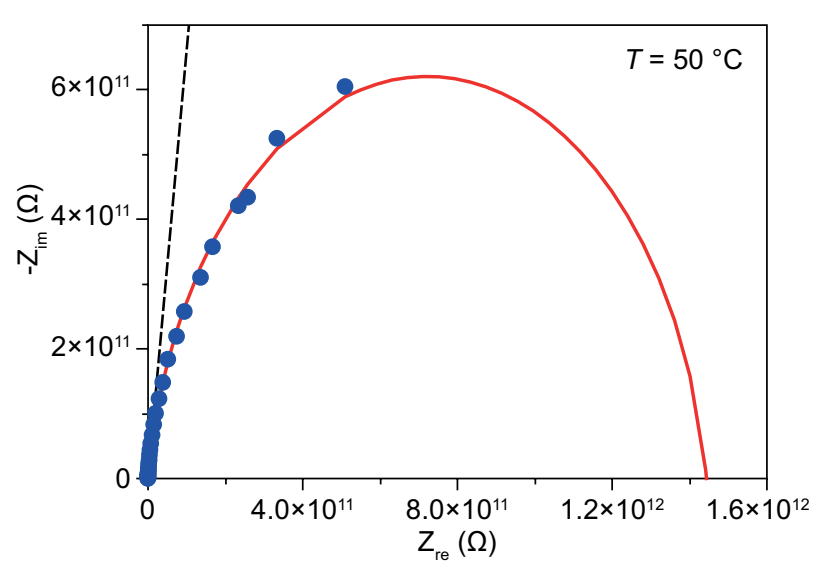

a)

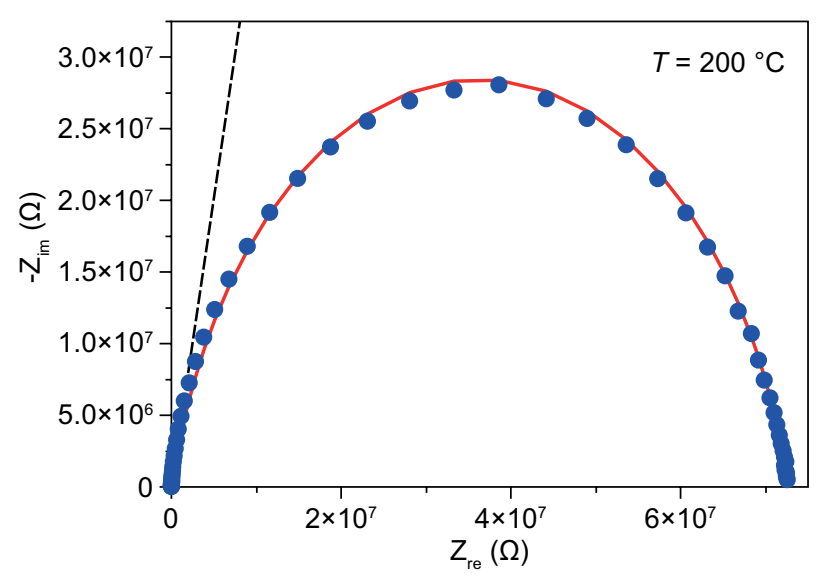

c)

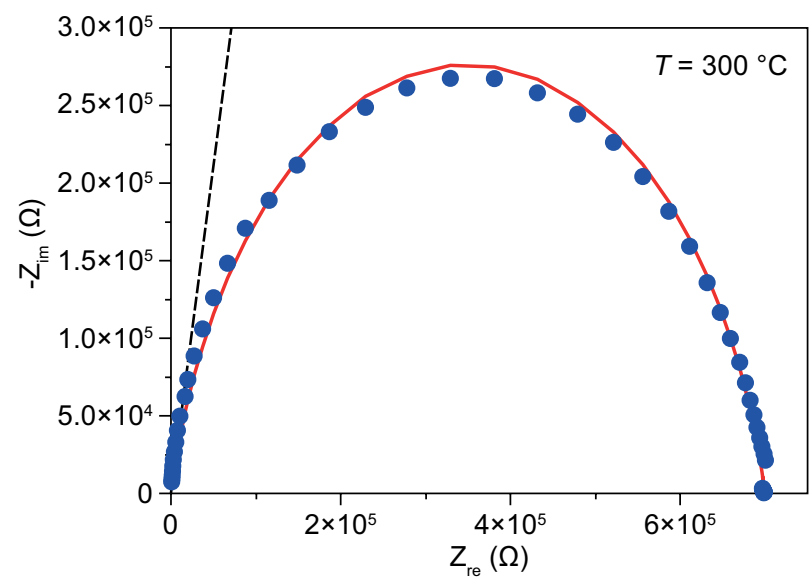

e)

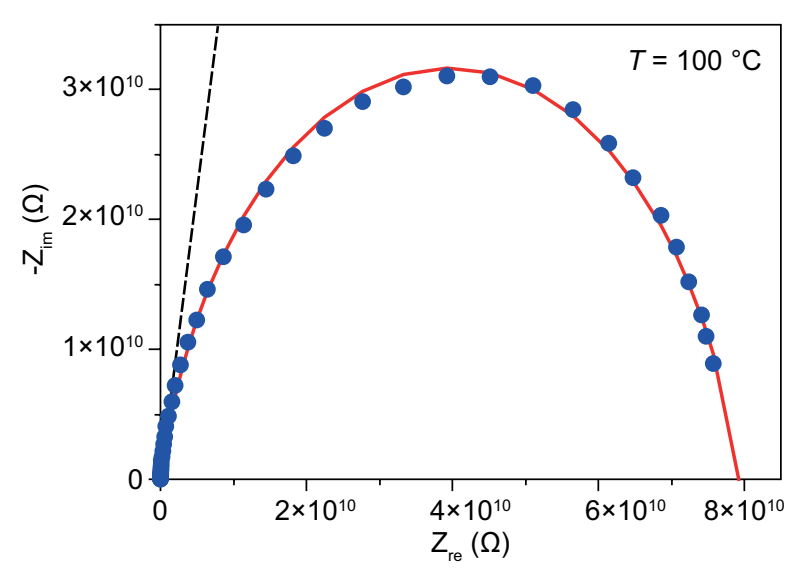

b)

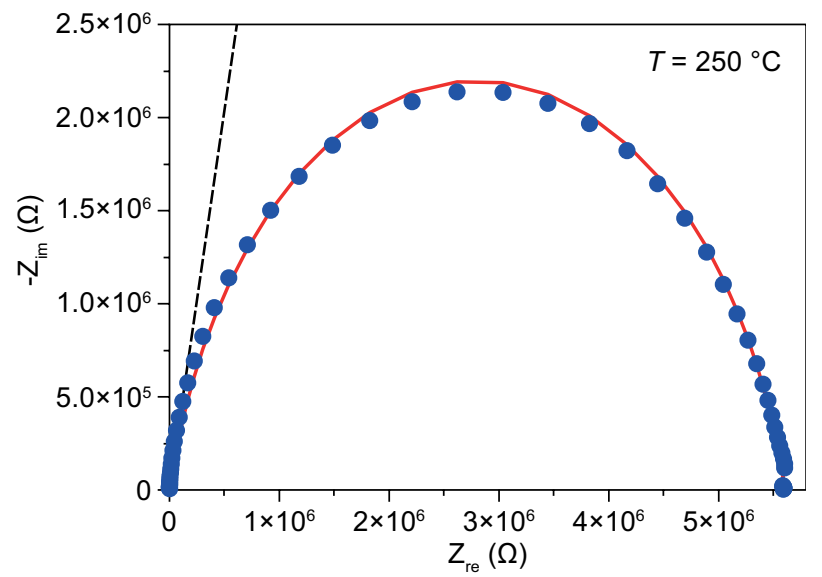

d)

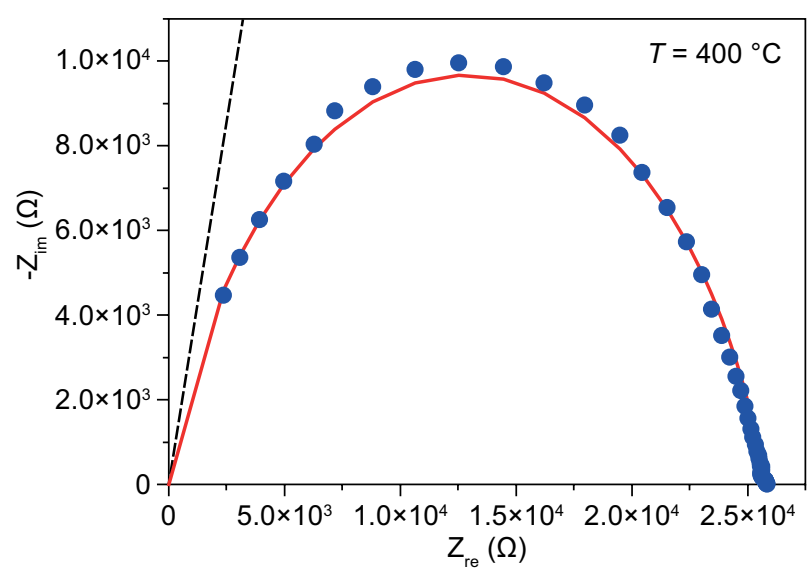

f)

Figure 3. Nyquist plots for temperatures $(50,100,200,250,300$, and 400$){ }^{\circ} \mathrm{C}$.

The ZARC complex impedance (Equation 4) can be written also as weighted superposition of Debye-like equations:

$Z_{\mathrm{B}}^{*}(\omega)=\frac{R}{1+\left(i \omega \tau_{\sigma \varepsilon}\right)^{\alpha}}=R \int_{-\infty}^{\infty} \frac{G\left(\alpha, \tau_{\sigma \varepsilon}, \ln \tau^{\prime}\right)}{1+i \omega \tau^{\prime}} d \ln \tau^{\prime}$

where $G$ is the distribution of relaxation time. For given $\tau_{\sigma \varepsilon}$ and $\alpha$ values, the distribution function $G$ can be obtained from formulas given in $[54,55]$. The distributions of relaxation times obtained for $\alpha$, and $\tau_{\sigma \varepsilon}$ parameters listed in the Table 2 are plotted in the Figure 5. The width of plotted relaxation time distributions is little bit increasing with increasing temperature. The analysis of the measured impedance data, shown in Figure 1, according to the Equation 11 models the system as a series of individual impedances of the type, described by the Equation 4, with quasi-continual change of characteristic time $\tau_{\sigma \varepsilon}$. In other words, the system under study is 
assumed to be spatially inhomogeneous, with spatially varying DC conductivity $\sigma_{\mathrm{DC}}$ and/or permittivity $\varepsilon$. According to the glass composition (Table 1), the $\sigma_{\mathrm{DC}}$ can be related to the ionic conductivity connected with the movement of alkali modifying cations $\left(\mathrm{Na}^{+}, \mathrm{K}^{+}, \mathrm{Ca}^{2+}\right.$, and $\mathrm{Ba}^{2+}$ ) can be supposed.

In the next step the RCL analysis of bulk complex impedance was performed based on the "First Principles" analysis of the electrical response in condensed phase

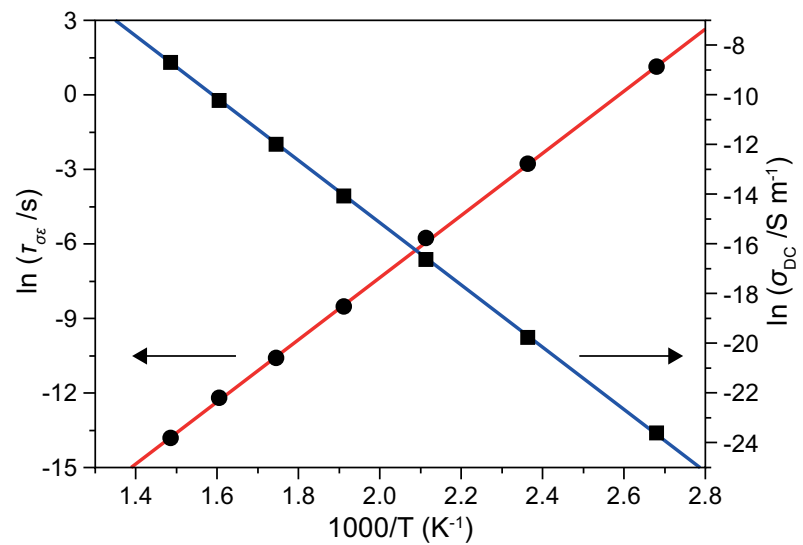

Figure 4. Temperature dependence of the mean relaxation time $\tau$ and DC conductivity $\sigma_{\mathrm{DC}}$.

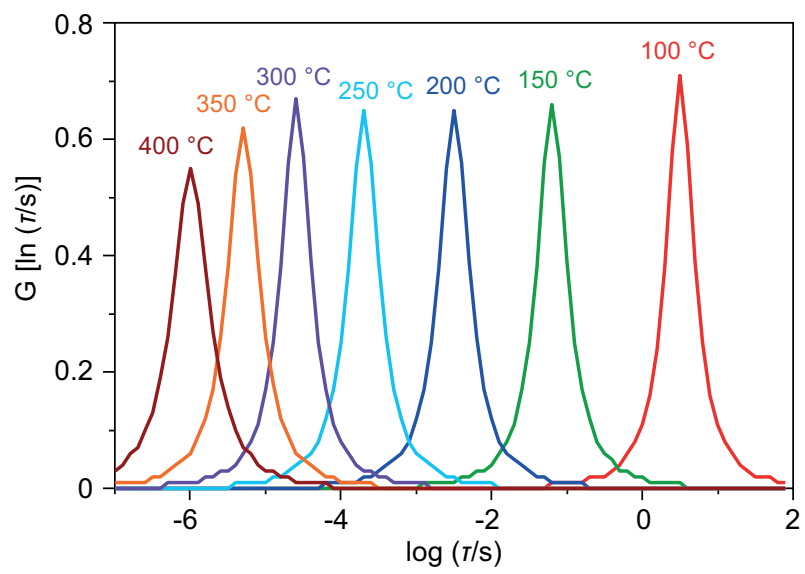

Figure 5. Distribution of relaxation times.

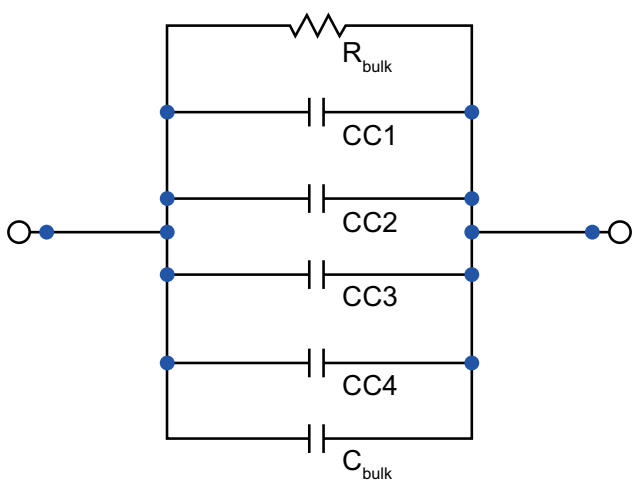

Figure 6. RCL equivalent circuit $\left(\mathrm{CC} 3=C_{\mathrm{MPC}}\right)$.
[51]. The numerically calculated electrical impedance $\mathrm{Z}^{*}(\omega)$ in this new type of response analysis can be approximated by a simple RCL network, where both the topology of the network and the individual R, C, L elements in it, are uniquely defined [57]. The topology of the resulting $\mathrm{R}, \mathrm{C}, \mathrm{L}$ network in this case is somewhat different from the ZARC analysis (Equation 11). Here, the system under study is assumed to be spatially homogeneous and the response is modeled as a parallel combination of a number of various physical processes taking place within the bulk of the sample, each physical process being represented by one RCL element.

The parallel arrangement of one resistor $\left(R_{\mathrm{Bulk}}-\mathrm{DC}\right.$ conduction), one capacitor $\left(C_{\mathrm{Bulk}}-\right.$ fast polarization) and four slow polarization processes (three universal capacitances $C_{\text {univ }}$ - Cole-Cole variety and one Debyelike Mobile Charge Polarisation capacitance $C_{\mathrm{MCP}}$ ) were sufficient to describe the data at all temperatures completely. The response of the system can be then formally described as an equivalent circuit consisting of parallel connection of one resistor, one capacitor and four ColeCole elements (Figure 6).

Due to character of the impedance data for $T=$ $=50{ }^{\circ} \mathrm{C}$ only two Cole-Cole elements and for $T=100{ }^{\circ} \mathrm{C}$ only three Cole-Cole elements were used. Obtained results are summarized in the Table 3 . The $\mathrm{R}_{\mathrm{Bulk}} * \mathrm{C}_{\mathrm{Bulk}}$ relaxation times $\tau_{\sigma \varepsilon}$ and specific resistivity $\rho_{\mathrm{B}}$ can be compared with the bulk relaxation time $\tau_{\sigma \varepsilon}$ and the DC resistivity $\rho_{\mathrm{B}}$, obtained from Nyquist plots (Table 2). The rough acceptable coincidence can be seen. Moreover the dependence of $\ln \left(\tau_{\sigma \varepsilon}\right)$ vs $1 / T$ (Figure 7) resulted in the linear equation:

$$
\ln \left(\tau_{\sigma \varepsilon}\right)=(-33.81 \pm 0.66)+\frac{12732 \pm 324}{T}
$$

with the activation energy value $E_{t}^{\neq}=(105.9 \pm 2.7) \mathrm{kJ} \cdot \mathrm{mol}^{-1}$ $=(1.10 \pm 0.03) \mathrm{eV}$ that is practically identical with the value obtained for $\tau_{\sigma \varepsilon}$ from Nyquist plots. Only the standard deviation of approximation $s_{\text {apr }}=0.34$ is significantly higher.

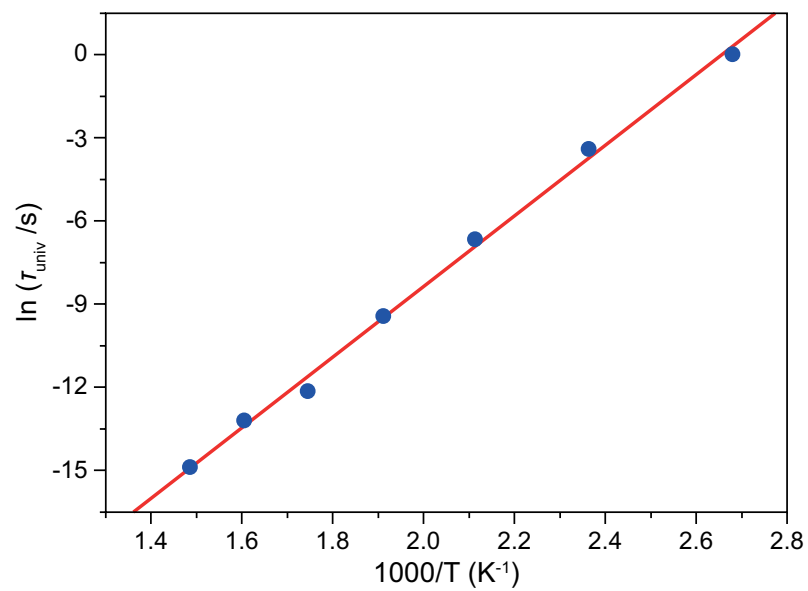

Figure 7. Temperature dependence of the bulk relaxation time $\tau_{\sigma \varepsilon}$. 
The distribution of relaxation times of Cole-Cole elements (Table 3) is plotted in the Figure 8 for all tem-peratures. The bulk relaxation time $\tau_{\sigma \varepsilon}$ is plotted as vertical lines. It can be seen that $\tau_{\sigma \varepsilon}$ is related and follows temperature dependence of the Cole-Cole 1 dielectric relaxation ( $\alpha$-relaxation in literature). This correlation between dc conductivity and the main and strongly temperature dependent dielectric $\alpha$-relaxation is known as $\mathrm{BNN}$ relation and it will be discussed in the next publication [56].

The Cole-Cole 3 relaxation process in Table 3 $\left(\mathrm{C}_{\mathrm{MCP}}\right)$ is qualitatively different from other Cole-Cole relaxation processes. As has been mentioned already

Table 3. Parameters of equivalent circuits.

\begin{tabular}{|c|c|c|c|c|}
\hline $\begin{array}{l}\text { Temp. } \\
\left({ }^{\circ} \mathrm{C}\right)\end{array}$ & Element & $\begin{array}{l}\tau_{\sigma \varepsilon} \\
(\mathrm{s})\end{array}$ & $\begin{array}{c}\rho_{\mathrm{B}} \\
(\Omega \cdot \mathrm{m})\end{array}$ & $\varepsilon_{\mathrm{r}, \mathrm{B}}$ \\
\hline 50 & RC-bulk & 12.10 & $2.29 \cdot 10^{11}$ & 6.37 \\
\hline 100 & RC-bulk & 1.02 & $1.73 \cdot 10^{10}$ & 6.70 \\
\hline 150 & RC-bulk & $3.33 \cdot 10^{-2}$ & $4.00 \cdot 10^{8}$ & 9.40 \\
\hline 200 & RC-bulk & $1.28 \cdot 10^{-3}$ & $1.70 \cdot 10^{7}$ & 8.50 \\
\hline 250 & RC-bulk & $8.05 \cdot 10^{-5}$ & $1.30 \cdot 10^{6}$ & 7.00 \\
\hline 300 & RC-bulk & $5.33 \cdot 10^{-6}$ & $1.64 \cdot 10^{5}$ & 6.62 \\
\hline 350 & RC-bulk & $1.86 \cdot 10^{-6}$ & $3.00 \cdot 10^{4}$ & 7.00 \\
\hline 400 & RC-bulk & $3.45 \cdot 10^{-7}$ & $6.00 \cdot 10^{3}$ & 6.50 \\
\hline $\begin{array}{c}\text { Temp. } \\
\left({ }^{\circ} \mathrm{C}\right)\end{array}$ & Element & $\begin{array}{c}\tau_{\text {univ }} \\
(\mathrm{s})\end{array}$ & $\alpha_{\mathrm{B}}$ & $\varepsilon_{\mathrm{r}}$ \\
\hline \multirow{2}{*}{50} & Cole-Cole1 & 300 & 0.40 & 23.0 \\
\hline & Cole-Cole 4 & $2.0 \cdot 10^{-8}$ & 0.60 & 1.6 \\
\hline \multirow{3}{*}{100} & Cole-Cole 1 & 5.75 & 0.46 & 24.2 \\
\hline & Cole-Cole 2 & 5000 & 0.70 & 300 \\
\hline & Cole-Cole 4 & $2.5 \cdot 10^{-8}$ & 0.60 & 2.5 \\
\hline \multirow{4}{*}{150} & Cole-Cole 1 & 0.20 & 0.45 & 25.0 \\
\hline & Cole-Cole 2 & 400 & 0.70 & 350 \\
\hline & Cole-Cole 3 & $4.0 \cdot 10^{4}$ & 0.965 & $2.0 \cdot 10^{4}$ \\
\hline & Cole-Cole 4 & $3.5 \cdot 10^{-8}$ & 0.70 & 2.9 \\
\hline \multirow{4}{*}{200} & Cole-Cole 1 & $6.0 \cdot 10^{-3}$ & 0.50 & 23.0 \\
\hline & Cole-Cole 2 & 6.50 & 0.70 & 170 \\
\hline & Cole-Cole 3 & $3.97 \cdot 10^{2}$ & 0.991 & $2.57 \cdot 10^{5}$ \\
\hline & Cole-Cole 4 & $2.0 \cdot 10^{-8}$ & 0.70 & 1.1 \\
\hline \multirow{4}{*}{250} & Cole-Cole 1 & $4.0 \cdot 10^{-4}$ & 0.50 & 23.0 \\
\hline & Cole-Cole 2 & 3.00 & 0.65 & 650 \\
\hline & Cole-Cole 3 & 21.0 & 0.999 & 2000 \\
\hline & Cole-Cole 4 & $2.0 \cdot 10^{-8}$ & 0.70 & 2.4 \\
\hline \multirow{4}{*}{300} & Cole-Cole 1 & $7.0 \cdot 10^{-5}$ & 0.55 & 23.0 \\
\hline & Cole-Cole 2 & 0.14 & 0.70 & 380 \\
\hline & Cole-Cole 3 & 3.0 & 0.990 & 3000 \\
\hline & Cole-Cole 4 & $1.0 \cdot 10^{-8}$ & 0.60 & 3.0 \\
\hline \multirow{4}{*}{350} & Cole-Cole 1 & $1.0 \cdot 10^{-5}$ & 0.57 & 21.0 \\
\hline & Cole-Cole 2 & $1.80 \cdot 10^{-2}$ & 0.60 & 245 \\
\hline & Cole-Cole 3 & 10.0 & 0.998 & $3.0 \cdot 10^{6}$ \\
\hline & Cole-Cole 4 & $1.0 \cdot 10^{-8}$ & 0.60 & 3.5 \\
\hline \multirow{4}{*}{400} & Cole-Cole 1 & $3.0 \cdot 10^{-6}$ & 0.57 & 24.0 \\
\hline & Cole-Cole 2 & $3.0 \cdot 10^{-4}$ & 0.80 & 80.0 \\
\hline & Cole-Cole 3 & $3.0 \cdot 10^{-3}$ & 0.998 & 200.0 \\
\hline & Cole-Cole 4 & $1.0 \cdot 10^{-8}$ & 0.60 & 4.0 \\
\hline
\end{tabular}

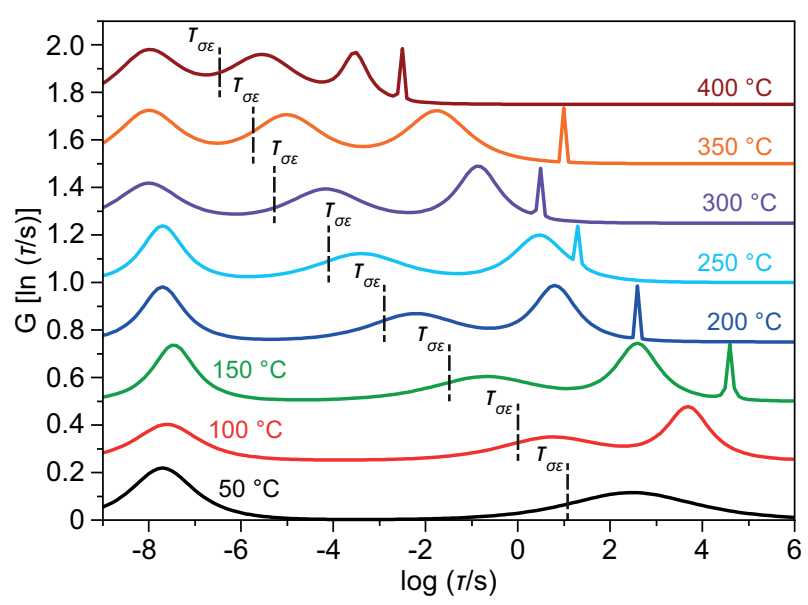

Figure 8. Distribution of relaxation times for equivalent circuit Cole-Cole elements.

before, it is not a real dielectric relaxation process, but rather a relaxation (electrical charge re-distribution), caused by the mobile charges in the system. It is almost Debye-like (small-like features at lowest frequencies in Figure 8) and the apparent relative dielectric constant (Figure 7) is un-physically high $\left(10^{+3}-10^{+6}\right)$. When properly analyzed, it should give the density of mobile charges in the studied barium crystal glass.

\section{CONCLUSIONS}

The proposed method of bulk properties separation based on the linear thickness dependence of complex impedance resulted in acceptable results mainly in the higher frequency region. The results obtained by the analysis of Nyquist diagrams resulted in distribution of conductopermitivity relaxation time with the distribution width slightly increasing with increasing temperature. The RCL analysis of bulk impedance spectra reveals four relaxation processes for temperature above $100{ }^{\circ} \mathrm{C}$ (only two relaxation processes for $20^{\circ} \mathrm{C}$ and three for $100{ }^{\circ} \mathrm{C}$ were found). Temperature dependences of conducto-permitivity relaxation time obtained by the analysis of Nyquist diagrams and by the RCL analysis resulted in the same value of activation energy of $104 \mathrm{~kJ} \cdot \mathrm{mol}^{-1}(1.10 \mathrm{eV})$ as expected. An interesting finding is a clear correlation of the bulk conducto-permittivity relaxation time with the "main" dielectric relaxation process, determined through RCL analysis. The two types of analysis (ZARC impedance analysis and RCL capacitance analysis) lead though to two different physical models for the studied glass. This aspect of the presented analysis requires further study.

\section{Acknowledgment}

This paper is created in the frame of the project FunGlass that has received funding from the European 
Union's Horizon 2020 research and innovation programme under grant agreement No 739566. This work was supported by the Slovak Grant Agency for Science under grant No. VEGA 1/0064/18, and by the SlovakCzech INTERREG project with ITMS code 304011 P822.

\section{REFERENCES}

1. Greaves G. N., Gurman S. J., Catlow C. R. A., Chadwick A. V., Houde-Walter S., Henderson C. M. B., Dobson B. R. (1991): A structural basis for ionic diffusion in oxide glasses. Philosophical Magazine A, 64, 5, 1059-1072. doi: $10.1080 / 01418619108204878$

2. Malcolm D. Ingram (1989): Ionic conductivity and glass structure. Philosophical Magazine B, 60, 6, 729-740. doi: 10.1080/13642818908209739

3. Kahnt H. (1991): Ionic Transport in Oxide Glasses and Frequency Dependence of Conductivity. Berichte der Bunsengesellschaft für physikalische Chemie, 95, 955-1162. doi: 10.1002/bbpc.19910950913

4. Mansour E. (2011): Structure and electrical conductivity of new $\mathrm{Li}_{2} \mathrm{O}-\mathrm{CeO}_{2}-\mathrm{B}_{2} \mathrm{O}_{3}$ glasses. Journal of Non-Crystalline Solids, 357, 1364-1369. doi: 10.1016/j.jnoncrysol.2010.09. 026

5. Rolinga B., Meyerb M., Bundeb A., Funkea K. (1998): Ionic ac and dc conductivities of glasses with varying modifier content. Journal of Non-Crystalline Solids, 226 , 138-144. doi: 10.1016/S0022-3093(97)00488-2

6. Roling B. (1998): Scaling properties of the conductivity spectra of glasses and supercooled melts. Solid State Ionics, 105, 185-193 doi: 10.1016/S0167-2738(97)00463-3

7. Roling B. (1999): What do electrical conductivity and electrical modulus spectra tell us about the mechanisms of ion transport processes in melts, glasses, and crystals? Journal of Non-Crystalline Solids, 244, 34-43. doi: 10.1016/S00223093(98)00847-3

8. Gowda V., Reddy N., Rao K. (2013): A new approach for understanding ion transport in glasses; Example of complex alkali diborate glasses containing lead, bismuth and tellurium oxides. Bulletin of Materials Science, 36, 71-85. doi:10.1007/s12034-013-0418-7

9. Macdonald J.R. (1992): Impedance spectroscopy. Annals of Biomedical Engineering, 20, 289-305. doi: 10.1007/ BF02368532

10. Barsoukov E., Macdonald J.R. (2005). Impedance Spectroscopy: Theory, Experiment, and Applications. $2^{\text {nd }} \mathrm{Ed}$. Wiley-Interscience.

11. Macdonald J. R. (2005): Impedance spectroscopy: Models, data fitting, and analysis. Solid State Ionics, 176, 1961-1969. doi: 10.1016/j.ssi.2004.05.035

12. Muccillo R., Muccillo E.N. S., França Y. V., Fredericci C., Prado M.O., Zanotto E.D. (2003): Impedance spectroscopy of a soda-lime glass during sintering. Materials Science and engineering: $A, 352,232-239$. doi: 10.1016/S09215093(02)00893-6

13. Braunger M. L., Escanhoela C. A. Jr., Ziemath E. C. (2014): Electrical conductivity of $\mathrm{Ag}-\mathrm{Na}$ ion exchanged sodalime glass. Solid State Ionics, 265, 55-60. doi: 10.1016/j. ssi.2014.07.015

14. Braunger M.L., Escanhoela C. A. Jr., Fier I., Walmsley L., Ziemath E.C. (2012): Electrical conductivity of silicate glasses with tetravalent cations substituting Si. Journal of Non-Crystalline Solids, 358, 2855-2861. doi: 10.1016/j. jnoncrysol.2012.07.013

15. Ziemath E.C., Escanhoela C.A.Jr., Braunger M.L. (2017): Comparison of activation energies for the electrical conductivity of silicate glasses obtained by DC and AC techniques. Solid State Ionics, 301, 146-151. doi: 10.1016/j.ssi. 2017.01.025

16. Prezas P.R., Soares M.J., Freire F.N.A., Graça M.P.F. (2015): Structural, electrical and dielectric characterization of $\mathrm{TeO}_{2}-\mathrm{WO}_{3}-\mathrm{Y}_{2} \mathrm{O}_{3}-\mathrm{Er}_{2} \mathrm{O}_{3}-\mathrm{Yb}_{2} \mathrm{O}_{3}$ glasses. Materials Research Bulletin, 68, 314-319. doi: 10.1016/j.materresbull. 2015.02.031

17. Sheoran A., Sanghi S., Rani S., Agarwal A., Seth V.P. (2009): Impedance spectroscopy and dielectric relaxation in alkali tungsten borate glasses. Journal of Alloys and compounds, 475, 804-809. doi: 10.1016/j.jallcom.2008.08.006

18. Ramteke D.D., Gedam R.S. (2014): Study of $\mathrm{Li}_{2} \mathrm{O}-\mathrm{B}_{2} \mathrm{O}_{3}-$ $-\mathrm{Dy}_{2} \mathrm{O}_{3}$ glasses by impedance spectroscopy. Solid State Ionics, 258, 82-87. doi: 10.1016/j.ssi.2014.02.006

19. Moguš-Milanković A., Šantić A., Karabulut M., Day D.E. (2003): Study of electrical properties of $\mathrm{MoO}_{3}-\mathrm{Fe}_{2} \mathrm{O}_{3}-\mathrm{P}_{2} \mathrm{O}_{5}$ and $\mathrm{SrO}-\mathrm{Fe}_{2} \mathrm{O}_{3}-\mathrm{P}_{2} \mathrm{O}_{5}$ glasses by impedance spectroscopy. II. Journal of Non-Crystalline Solids, 330, 128-141. doi: 10.1016/j.jnoncrysol.2003.08.050

20. Sharma M.V.N.V.D., Sarma A.V., Rao R.B. (2009): Electrical characterization and relaxation behavior of lithiumindium- phosphate glasses via impedance spectroscopy. Turkish Journal of Physics. 33, 87-100. doi: 10.3906/fiz0803-7

21. Maia L. F., Rodrigues A.C.M. (2004): Electrical conductivity and relaxation frequency of lithium borosilicate glasses. Solid State Ionics, 168, 87-92. doi: 10.1016/j.ssi. 2004.02.016

22. Terny S., De la Rubia M.A., Alonso R.E., de Frutos J., Frechero M.A. (2015): Structure and electrical behavior relationship of a magnesium-tellurite glass using Raman and impedance spectroscopy. Journal of Non-Crystalline Solids, 411, 13-18. doi: 10.1016/j.jnoncrysol.2014.12.026

23. Réau J.M., Rossignol S., Tanguy B., Paris M.A., Rojo J.M., Sanz J. (1995): $\mathrm{Li}^{+}$ion mobility in $\mathrm{TeO}_{2}-\mathrm{LiO}_{0.5}$ $-\mathrm{LiX}(\mathrm{X}=\mathrm{F}, \mathrm{Cl})$ glasses determined by ${ }^{7} \mathrm{Li} \mathrm{NMR}$ and impedance spectroscopy. Solid State Ionics, 80, 283-290. doi: 10.1016/0167-2738(95)00147-X

24. Pereira R., Gozzo C.B., Guedes I., Boatner L.A., Terezo A.J., Costa M.M. (2014): Impedance spectroscopy study of $\mathrm{SiO}_{2}-\mathrm{Li}_{2} \mathrm{O}: \mathrm{Nd}_{2} \mathrm{O}_{3}$ glasses. Journal of Alloys and Compounds, 597, 79-84. doi: 10.1016/j.jallcom.2014.01.151

25. Amara, C.B., Hammami, H., Fakhfakh, S. (2019): Effect of iron oxide on the electrical conductivity of sodalime silicate glasses by dielectric spectroscopy Journal of Materials Science: Materials in Electronics, 30, 13543-13555. doi: 10.1007/s10854-019-01722-1

26. da Rocha M.S.F., Pontuschka W.M., Blak A.R. (2003): Radiation induced capacitance in barium aluminoborate glasses. Journal of Non-Crystalline Solids, 321, 29-36. doi: 10.1016/S0022-3093(03)00087-5

27. Queiroz C., Figueiredo F., Fernandes M., Frade J. (2004): Crystallisation of bulk silicate-phosphate samples studied by impedance spectroscopy. Physics and Chemistry of Glasses, 45, 71-74.

28. Lefterova E., Kanazirsky I., Bliznakov S., Ilcheva V., 
Dimitriev Y. (2005): Impedance and structural investigation of glasses from the system $2 \mathrm{TeO}_{2}-\mathrm{V}_{2} \mathrm{O}_{5}-\mathrm{Ag}_{2} \mathrm{O}-\mathrm{AgI}$. Bulgarian Chemical Communications, 37, 11.

29. Sklepić K., Vorokhta M., Mošner P., Koudelka L., MogušMilanković A. (2014): Electrical Mobility of Silver Ion in $\mathrm{Ag}_{2} \mathrm{O}-\mathrm{B}_{2} \mathrm{O}_{3}-\mathrm{P}_{2} \mathrm{O}_{5}-\mathrm{TeO}_{2}$ Glasses The Journal of Physical Chemistry B, 118, 12050-12058. doi: 10.1021/jp5073796

30. Koushik M., Varma K.B.R. (2009): Structural, dielectric, impedance and optical properties of $\mathrm{CaBi}_{2} \mathrm{~B}_{2} \mathrm{O}_{7}$ glasses and glass-nanocrystal composites. Materials Chemistry and Physics, 117, 494-499. doi: 10.1016/j.matchemphys.2009. 06.044

31. Medina F., Furman E., Lanagan M. (2010): Dielectric Properties of Reduced Heterogeneous Silica-Titania Glasses. International Journal of Applied Glass Science, 1, 358-367. doi: 10.1111/j.2041-1294.2010.00033.x.

32. YongSuk Y. (2010): Impedance analysis and low frequency dispersion behavior of $\mathrm{Bi}_{4} \mathrm{Ti}_{3} \mathrm{O}_{12}$ glass. Journal of the Korean Physical Society, 56, 462-466. doi: 10.3938/jkps. 56.462

33. Satya G.R.P., Siripuram R., Sripada S. (2019): Impedance Analysis of $\mathrm{TeO}_{2}-\mathrm{SeO}_{2}-\mathrm{Li}_{2} \mathrm{O}$ Nano Glass System. Results in Physics. 13, 102133. doi: 10.1016/j.rinp.2019.02.069

34. Bala R., Agarwal A., Sanghi S., Sanjay A. (2019): Electrical characterization and dielectric behavior of $\mathrm{PbO}$ $-\mathrm{Bi}_{2} \mathrm{O}_{3}-\mathrm{Ga}_{2} \mathrm{O}_{3}$ glasses. AIP Conference Proceedings, 2142, 070032. doi: 10.1063/1.5122424

35. Queiroz C., Fernandes M., Frade J. (2006): Non-isothermal crystallisation of $\mathrm{SiO}_{2}-\mathrm{MgO}-\mathrm{K}_{2} \mathrm{O}-3 \mathrm{CaO}-\mathrm{P}_{2} \mathrm{O}_{5}$ glass studies by impedance spectroscopy. Materials Science Forum, 514-516,1078-1082. doi: 10.4028/www.scientific.net/MSF. 514-516.1078.

36. Queiroz C. M., Fernandes M. H. F.V., Frade Jorge R. (2006): Isothermal crystallisation of a glass from the $3 \mathrm{CaO} . \mathrm{P}_{2} \mathrm{O}_{5}-\mathrm{SiO}_{2}-\mathrm{MgO}-\mathrm{K}_{2} \mathrm{O}$ system studied by impedance spectroscopy. Materials Science Forum, 514-516, 1073-1077. doi: 10.4028/www.scientific.net/MSF.514-516. 1073

37. Queiroz C.A., Figueiredo F.M., Fernandes M. H. F.V., Frade J.R. (2004): Crystallisation of bulk silicate-phosphate samples studied by impedance spectroscopy. Physics and Chemistry of Glasses, 45, 71-74.

38. Shimakawa K. (1981): On the correlation between electrical conduction and dielectric relaxation in oxide glasses. Journal of Non-CrystallineSolids, 43, 145-149. doi: 10.1016/ 0022-3093(81)90181-2

39. Wook S. D., Tomozawa M. (1997): Electrical and dielectric relaxation in silica glasses at low temperature. Journal of Non-Crystalline Solids, 211, 237-249. doi: 10.1016/S00223093(96)00638-2

40. Tan C.Z., Arndt J. (1994): Static dielectric constant and dielectric relaxation of densified $\mathrm{SiO}_{2}$ glass. J. Non-Cryst. Solids, 169, 143-149. doi: 10.1016/0022-3093(94)90233-X

41. Dutta A., Sinha T.P., Jenab P., Adak S. (2008): AC conductivity and dielectric relaxation in ionically conducting soda-lime-silicate glasses. Journal of Non-Crystalline Solids, 354,3952-3957. doi: 10.1016/j.jnoncrysol.2008.05.028 42. Majhi K., Varma B.R.K. (2010): Dielectric relaxation in
$\mathrm{CaO}-\mathrm{Bi}_{2} \mathrm{O}_{3}-\mathrm{B}_{2} \mathrm{O}_{3}$ Glasses. International Journal of Applied Ceramic Technology, 7, E89-E97.doi:10.1111/j.1744-7402. 2009.02438.x

43. Tomozawa M., Doremus R.H. (1974): Experimental measurements of dielectric relaxation in glass. Journal of NonCrystalline Solids, 14, 54-64. doi: 10.1016/0022-3093(74) 90018-0

44. Taylor H. E. (1956): The dielectric relaxation spectrum of glass. Transactions of the Faraday Society, 52, 873-881. doi: 10.1039/TF9565200873

45. Barde R.V., Waghuley S.A. (2012): DC electrical conductivity of $\mathrm{V}_{2} \mathrm{O}_{5}-\mathrm{P}_{2} \mathrm{O}_{5}$ binary glassy systems Journal of Physics: Conference Series, 365, 012019. doi: 10.1088/ 1742-6596/365/1/012019

46. Ghosh A., Sural M., Sen S. (1998):Electrical properties of some alkaline earth vanadate glasses. Journal of Physics: Condensed Matter, 10, 7567. doi: 10.1088/0953-8984/10/ $34 / 010$

47. MacCrone R.K.(1978). Electrical and dielectric properties of borate glasses. in: Pye D.L., Fréchette V.D., Kreidl N.J. (Eds.): Borate glasses. Plenum Press. pp. 491-508.

48. Saha S.K., Chakravorty D. (1992): Dielectric Relaxation in Oxide Glasses. apanese Journal of Applied Physics, 31, 3642-3648. doi: 10.1143/JJAP.31.3642

49. Černá A., Hruška B., Tokarčíková D., Chromčíková M., Liška M. (2018): Optical microscopy, Raman spectroscopy, and AFM study of heavy weathered surface of barium crystal glass. Chemical Papers, 72, 2153-2158. doi:10.1007/s11696-018-0464-0

50. Ozarem M.E., Tribollet B.(2017). Electrochemical Impedance Spectroscopy. $2^{\text {nd }}$ Edition, John Wiley \& Sons.

51. Viščor P., Viščor M. (2019): Electrical Impedance Spectroscopy: First Principles analysis and simulations of electrical response in the classical range of frequencies below $1 \mathrm{THz}$ and the resulting new role of Electrical Impedance Spectroscopy in electrical characterization within Condensed Matter Physics. Pure and Applied Chemistry, 91, 1832-1856. doi: 10.1515/pac-2018-1107.

52. http://www.consultrsr.net/resources/eis/zarc.htm, January 2020.

53. Orazem M.E., Shukla P., Membrino M.A. (2002): Extension of the measurement model approach for deconvolution of underlying distributions for impedance measurements. Electrochimica Acta, 47, 2027-2034. doi: 10.1016/S00134686(02)00065-8

54. Zorn R. (1999): Applicability of distribution function for the Havriliak-Negami spectral function. Journal of Polymer Science Part B: Polymer Physics, 37, 1043-1044. doi: 10.1002/(SICI)1099-0488(19990515)37:10<1043:AIDPOLB9>3.0.CO;2-H.

55. https://en.wikipedia.org/wiki/Havriliak $\%$ E2\%80\%93Negami relaxation, January 2020.

56. Viščor P. (2020). Personal communication.

57. Viscor P., Vedde J. (1997). Method and Apparatus for determining characteristic electrical material parameters in semi-conducting materials. U.S. Patent no.5 627479 (May 6, 1997), European Patent no. EP 0672257 B1 (February 4, 1998). 